\title{
Genetic control of postoperative systemic inflammatory reaction and pulmonary and renal complications after coronary artery surgery
}

\author{
Mario Gaudino, MD \\ Augusto Di Castelnuovo, $\mathrm{MS}^{\mathrm{d}}$ \\ Roberto Zamparelli, MD ${ }^{\mathrm{b}}$ \\ Felicita Andreotti, MD ${ }^{\mathrm{c}}$ \\ Francesco Burzotta, MD ${ }^{c}$ \\ Licia lacoviello, MD, $\mathrm{PhD}^{\mathrm{d}}$ \\ Franco Glieca, MD ${ }^{a}$ \\ Francesco Alessandrini, MD \\ Giuseppe Nasso, MD \\ Maria Benedetta Donati, $\mathrm{MD}^{\mathrm{d}}$ \\ Attilio Maseri, MD ${ }^{\mathrm{c}}$ \\ Rocco Schiavello, MD \\ Gianfederico Possati, MD
}

From the Departments of Cardiac Surgery, ${ }^{a}$ Anesthesiology, ${ }^{\mathrm{b}}$ and Cardiology, ${ }^{\mathrm{c}}$ Catholic University, Rome, Italy, and the "Angela Valenti" Laboratory of Genetic and Enviromental Risk Factors for Thrombotic Disease, Department of Vascular Medicine and Pharmacology, ${ }^{\mathrm{d}}$ Consorzio Mario Negri Sud, Santa Maria Imbaro, Italy.

Received for publication Sept 9, 2002; revisions requested Oct 10, 2002; revisions received Oct 12, 2002; accepted for publication Oct 29, 2002.

Address for reprints: Mario Gaudino, MD, Policlinico Universitario A. Gemelli, Divisione di Cardiochirurgia, Largo A. Gemelli 8, 00168, Rome, Italy (E-mail: mgaudino@tiscalinet.it).

J Thorac Cardiovasc Surg 2003;126: $1107-12$

Copyright (C) 2003 by The American Association for Thoracic Surgery

$0022-5223 / 2003 \$ 30.00+0$

doi:10.1016/S0022-5223(03)00396-9
Background: Although some data suggest that the individual genetic predisposition for developing major or minor degrees of postoperative systemic inflammatory reaction may influence postoperative morbidity, this hypothesis has not been clinically tested to date.

Methods and Results: The $-174 \mathrm{G} / \mathrm{C}$ polymorphism of the promoter of the interleukin 6 gene was determined preoperatively in 111 consecutive patients submitted to primary isolated coronary artery bypass. The results of the genetic analysis were then correlated with the postoperative interleukin 6 levels and the development of postoperative renal and pulmonary complications. G homozygotes had significantly higher interleukin 6 levels postoperatively $(P<.0001$ for the difference between areas under the curve). These patients also had worse postoperative pulmonary and renal function. The mean perioperative difference in serum creatinine, potassium, and nitrogen was $0.82 \pm 0.34,0.99 \pm 0.44$, and $10.1 \pm 7.8$ $\mathrm{mg} / \mathrm{dL}$ versus $0.18 \pm 0.14,0.15 \pm 0.48$, and $2.6 \pm 4.1 \mathrm{mg} / \mathrm{dL}$ for GG versus non-GG carriers $(P<.0001)$, respectively. The mean respiratory index at 6 and 12 hours was $2.9 \pm 0.8$ and $2.8 \pm 0.3$ versus $2.1 \pm 0.5$ and $1.3 \pm 0.1$, respectively $(P$ $<.0001)$. The mean duration of mechanical ventilation was $22.5 \pm 2.1$ versus 12.7 \pm 6.7 hours $(P<.01)$. A correlation was found between postoperative interleukin 6 levels and renal and pulmonary complications.

Conclusion: The interleukin $6-174 \mathrm{G} / \mathrm{C}$ polymorphism modulates postoperative interleukin 6 levels and is associated with the degree of postoperative renal and pulmonary dysfunction and in-hospital stay after coronary surgery.

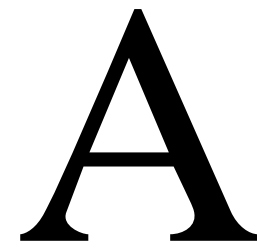

lthough there is general agreement that the inflammatory reaction induced by extracorporeal circulation plays a major role in determining morbidity after cardiac surgery, ${ }^{1,2}$ the modulators of the systemic damage are not yet fully understood, and, most important, the development of postoperative complications is largely unpredictable at the moment (with the exception of cases with clear-cut preoperative organ dysfunction). ${ }^{3}$ 
The kidneys and the lungs are probably the main target of the postoperative systemic inflammatory reaction. A subclinical degree of renal and pulmonary impairment is thought to occur after almost any cardiac operation, and pulmonary and renal complications account for a great part of postoperative morbidity after cardiac surgical procedures. $^{4-6}$

The individual genetic background could theoretically modulate the magnitude of the postoperative systemic inflammatory reaction and, thus, contribute to a greater or lesser propensity for both renal and pulmonary complications.

This hypothesis is supported by recent preliminary data from our group showing that postoperative levels of interleukin 6 (IL-6, one of the principal mediators of the inflammatory response to cardiopulmonary bypass $[\mathrm{CPB}]$ ) are genetically modulated by the single-base promoter mutation IL-6 - $174 \mathrm{G} / \mathrm{C}$ and that the G homozygosis for this polymorphism predicts postoperative in-hospital stay after coronary surgery. However, in this preliminary analysis, postoperative outcome was measured by simple clinical indexes and no correlation between genetic status and morbidity could be found. ${ }^{7}$

The present study investigated, in the same cohort of cases, whether the described longer postoperative course of G homozygotes is related to a greater incidence of pulmonary and renal dysfunction (evaluated using sensible indexes) and if postoperative IL-6 levels could be correlated with the development of pulmonary and renal complications.

\section{Patients and Methods \\ Patient Population}

From January 1998, all patients scheduled to undergo elective isolated coronary revascularization surgery at our institution were screened for inclusion in a study on the hemostatic and inflammatory reaction to $\mathrm{CPB}$ (Fibrinolisi ed Infiammazione nella Fase Acuta [FIFA] study). Preliminary results of this study have already been published. ${ }^{7,8}$

To maximize homogeneity and to reduce patient-related confounding factors, rigorous exclusion criteria were adopted to obtain a highly selected population of patients with triple vessel surgical coronary artery disease without concomitant systemic pathologies. Exclusion criteria were as follows: (1) associated cardiac or noncardiac surgical procedures; (2) age greater than 80 years; (3) single vessel disease; (4) emergency or urgent revascularization; (5) left ventricular ejection fraction less than 0.30 ; (6) significant carotid artery disease ( $>50 \%$ stenosis); (7) previous cerebrovascular accident; (8) long-term dialysis; (9) respiratory or renal insufficiency (defined, respectively, as a preoperative creatinine level of $\geq 2.0 \mathrm{mg} / \mathrm{dL}$ and a preoperative $\mathrm{PO}_{2}$ of $\leq 60 \mathrm{~mm} \mathrm{Hg}$ or $\mathrm{PCO}_{2}>50 \mathrm{~mm} \mathrm{Hg}$ in current air and/or a preoperative forced expiratory volume in 1 second $\left[\mathrm{FEV}_{1}\right]<1.25 \mathrm{~L}$ or $<75 \%$ of the normal value); (10) hemorrhagic conditions; (11) active infection; and, (12) chronic anti-inflammatory therapy (defined as the daily use of either corticosteroids or nonsteroidal anti-inflammatory drugs for more than 1 month). Data collection ended in May 1999 and, for this period, a total of 113 cases were included. The study received ethical committee approval and all included patients gave their consent to participate. Genetic analysis could not be performed in 2 cases so that the present report refers to 111 patients.

\section{Surgical Technique}

The anesthetic procedures were standardized for all patients: they received their medication until the day of the operation and were premedicated with diazepam $(0.15 \mathrm{mg} / \mathrm{kg})$, morphine $(0.15 \mathrm{mg} /$ $\mathrm{kg})$, and scopolamine $(0.01 \mathrm{mg} / \mathrm{kg})$. After induction with sodium thiopental (2-3 mg/kg), balanced anesthesia was performed with isoflurane, fentanyl, and boluses of midazolam and propofol as needed to maintain hypnosis. Muscle relaxation was ensured by the administration of pancuronium bromide $(0.1 \mathrm{mg} / \mathrm{kg})$. Anticoagulation was obtained with heparin $300 \mathrm{IU} / \mathrm{kg}$, and an activated clotting time greater than 480 seconds was maintained. Heparin neutralization was achieved with protamine hydrochloride (1.3 $\mathrm{mg} / \mathrm{mg}$ heparin). In no patients were agents with renal effects used preoperatively and in no cases were antifibrinolytic drugs used in the perioperative period. All surgical procedures were performed in standard fashion by the same surgical team through median sternotomy and with $\mathrm{CPB}$.

As the FIFA study had as secondary end point the assessment of the effect of CPB temperature on postoperative inflammatory and fibrinolytic activation, patients were randomized to a CPB nasopharyngeal temperature of $37^{\circ} \mathrm{C}$ (55 patients) or $26^{\circ} \mathrm{C}(58$ patients). The results of the study on CPB temperature have been described in a separate report ${ }^{8}$; in summary, no differences in inflammatory and fibrinolytic activation were found between patients operated on with normothermic versus hypothermic CPB.

Myocardial protection was always accomplished by antegrade intermittent blood cardioplegia isothermic to $\mathrm{CPB}$ temperature.

\section{IL-6 Promoter Polymorphism Analysis}

For genetic analyses, blood was drawn immediately before surgery. Citrated samples were centrifuged without delay at $3000 \mathrm{~g}$ for 20 minutes; cellular pellets were stored at $-20^{\circ} \mathrm{C}$. DNA was extracted by standard techniques. -174 G/C IL- 6 promoter genotyping was performed according to a method described previously. ${ }^{9}$ This polymorphism was chosen for its demonstrated role in the control of plasma IL-6 levels. ${ }^{9}$

\section{IL-6 Dosage}

The plasma concentrations of IL-6 were determined in each patient (1) preoperatively; (2) 24, 48, and 72 hours after the operation; and, (3) at hospital discharge. The assay was performed in a core laboratory blinded to the patients' status using the IL-6 Human Biotrak Elisa System (Amersham Pharmacia Biotech Inc, Piscataway, NJ).

\section{Evaluation of Postoperative Outcome}

To avoid investigator-related biases, all the physicians involved in patients' care were blinded to the results of the genetic and biochemical analyses, which were performed in a core laboratory by operators blinded to patients' clinical course. The in-hospital clinical courses of all patients, including major and minor postop- 
erative complications, mean duration of mechanical ventilation, and stay in the intensive care unit, were prospectively recorded. Daily blood samples were obtained postoperatively until hospital discharge, per institutional routine, and used for the clinical management after surgery.

To evaluate even subclinical variations of the pulmonary function, the respiratory index (defined as $\mathrm{P}(\mathrm{A}-\mathrm{a}) \mathrm{O}_{2} / \mathrm{PaO}_{2}$, where $\mathrm{P}(\mathrm{A}-\mathrm{a}) \mathrm{O}_{2}$ is the alveolar-arterial difference for $\mathrm{PO}_{2}$ and $\mathrm{PaO}_{2}$ the arterial $\mathrm{PO}_{2}$ ) was calculated for each patient at 6 and 12 hours.

For a sensible evaluation of the renal function the following parameters were adopted:

1. Perioperative difference in serum creatinine, nitrogen, and potassium ( $\Delta$-Creat, $\Delta$-BUN, and $\Delta$-K, respectively): these indexes were evaluated by calculating the difference between the highest in-hospital postoperative value and the preoperative value (defined as the one obtained closest to surgery), according to a method previously validated by others. $^{10}$

2. Need for dopamine stimulus at renal dosage $\left(3.0 \mu \mathrm{g} \cdot \mathrm{kg}^{-1}\right.$ - $\min ^{-1}$ ) and/or need for extra diuretic stimulus (defined as a furosemide dosage $>1 \mathrm{mg} / \mathrm{kg}$ in 24 hours or furosemide plus any other diuretic): both these therapeutic measures were decided by the cardiac anesthesiologist on duty on a clinical basis and to maintain a diuresis $>0.5 / \mathrm{mL} \cdot \mathrm{kg}^{-1}$. $\min ^{-1}$.

\section{Statistical Analysis}

The $\chi^{2}$ or Fisher exact tests were used to compare discrete parameters. To remove skewness, logarithms were applied to data when appropriate, although untransformed data are shown. Continuous variables (presented as means $\pm \mathrm{SD}$ ) were compared by parametric (or nonparametric, when data remained skewed) analysis of variance. Relationships among continuous variables were measured by the Spearman correlation test and multivariate regression analysis. Association between genotype and categorical variables was assessed with the use of multivariate logistic regression analysis in a model that included the major clinical variables and the most accepted risk factors for renal and pulmonary complications. These are as follows: (1) age; (2) sex; (3) preoperative creatinine value; (4) CPB temperature; (5) hypertension; (6) hypercholesterolemia; (7) previous myocardial infarction, angina, or cardiac failure; (8) major and minor postoperative complications; (9) time spent in the intensive care unit; and, (10) time spent in the hospital.

Differences in continuous variables according to genotypes were assessed with a multivariate analysis of variance (MANOVA) approach, using general linear models (GLM procedure for SAS), including as covariates the same variables used in logistic regression. MANOVA was used to test the hypothesis of no overall effect of polymorphism on the set of indexes of pulmonary or renal complications. The area under the curve of the postoperative IL-6 values was calculated by the Simpson method with the trapezium division areas: [(Y preoperative + Y 24 hours postoperative $) / 2 * \mathrm{~T} 1]+[(\mathrm{Y} 24$ hours postoperative $+\mathrm{Y} 48$ hours postoperative $) / 2 * \mathrm{~T} 2]+[(\mathrm{Y} 48$ hours postoperative $+\mathrm{Y} 72$ hours postoperative $) / 2 * \mathrm{~T} 3]+[(\mathrm{Y} 72$ hours postoperative $+\mathrm{Y}$ predischarge) $/ 2 * \mathrm{~T} 4$ ], where T1-T4 are the different time intervals in hours ( $\mathrm{T} 1$, from the preoperative time to 24 hours postoperatively; T2, from 24 to 48 hours postoperatively; T3, from 48 to 72
TABLE 1. Postoperative mortality and morbidity in the whole series of patients

\begin{tabular}{lc}
\hline Characteristics & $\begin{array}{c}\text { Frequency or } \\
\text { mean } \pm \text { SD }\end{array}$ \\
\hline Death & 2 \\
Stroke & 0 \\
Myocardial infarction & 5 \\
Sepsis & 1 \\
Shock & 1 \\
Reoperation & 2 \\
Postoperative bleeding (mL/24 h) & $753 \pm 218$ \\
Revision for bleeding & 8 \\
Atrial fibrillation & 24 \\
Need for blood transfusion & 28 \\
Mean intensive care unit stay (d) & $2.2 \pm 2.7$ \\
Mean postoperative stay (d) & $6.0 \pm 3.0$ \\
\hline
\end{tabular}

As already reported, ${ }^{7}$ no differences in clinical outcome were found between $\mathrm{GG}$ and $\mathrm{C}$-allele carriers. The rate of major in-hospital complications and death was $8 \%$ for $\mathrm{GG}$ versus $2 \%$ for $C$ carriers, $P=.1$.

hours postoperatively; and, T4, from 72 hours postoperatively to before discharge) and $\mathrm{Y}$ is the IL-6 value.

Analyses were carried out with the SAS statistical package (SAS/STAT User Guide, version 8.1, SAS Institute, Inc, Cary, $\mathrm{NC})$.

\section{Results}

\section{Overall Clinical Results}

Detailed in-hospital clinical results of this cohort of patients have already been described in detail elsewhere ${ }^{8}$ and are summarized in Table 1. Two in-hospital deaths occurred due to massive pulmonary embolism (on the third postoperative day) and myocardial infarction (8 days after the operation). Postoperatively, 4 patients had nonfatal myocardial infarction, 1 patient had a septic syndrome, and 2 patients had to be reoperated on for clinical or instrumental evidence of graft malfunction. Eight patients needed a surgical revision of the hemostasis and 28 needed a blood transfusion. Mean stay in the intensive care unit and in the hospital after surgery were $2.2 \pm 3.7$ and $6.0 \pm 3.0$ days, respectively.

\section{IL-6 Promoter Polymorphism Analysis}

Genetic analysis revealed GG genotype in 62 patients, GC in 39, and $\mathrm{CC}$ in 10, a distribution that did not differ significantly from that predicted by the Hardy-Weinberg equilibrium law $(P=.29)$. Allele frequencies were 0.73 (95\% CI: 0.68-0.79) for G and 0.27 (95\% CI: 0.21-0.32) for C. $\mathrm{G}$ homozygotes did not differ significantly from $\mathrm{C}$-allele carriers for baseline clinical and surgical characteristics (see Table $2, P>.05$ for all comparisons).

\section{Evaluation of Postoperative IL-6 Levels}

There was a significant effect of genotype on IL-6 levels; G homozygotes had significantly higher IL-6 levels postoper- 
TABLE 2. Preoperative and intraoperative characteristics of the patients according to IL-6 promoter polymorphism

\begin{tabular}{|c|c|c|c|}
\hline Characteristics & $\begin{array}{c}\text { All } \\
\text { (n= 111) }\end{array}$ & $\begin{array}{c}\text { GG } \\
(n=62)\end{array}$ & $\begin{array}{l}C G+C C \\
(n=49)\end{array}$ \\
\hline Age (y) & $61 \pm 9$ & $61 \pm 9$ & $61 \pm 8$ \\
\hline Male & $103(93 \%)$ & $59(95 \%)$ & $44(90 \%)$ \\
\hline Current smoker & $44(42 \%)$ & $24(39 \%)$ & $20(45 \%)$ \\
\hline Hypercholesterolemia & $29(27 \%)$ & $16(26 \%)$ & $13(28 \%)$ \\
\hline Hypertension & $70(65 \%)$ & $40(65)$ & $30(65 \%)$ \\
\hline Diabetes & $23(21 \%)$ & $13(21 \%)$ & $10(22 \%)$ \\
\hline $\begin{array}{l}\text { Preoperative serum } \\
\text { creatinine (mg/dL) }\end{array}$ & $1.1 \pm 0.4$ & $1.1 \pm 0.6$ & $1.1 \pm 0.1$ \\
\hline $\begin{array}{l}\text { Previous myocardial } \\
\text { infarction }\end{array}$ & $57(53 \%)$ & $31(52 \%)$ & $26(54 \%)$ \\
\hline $\begin{array}{l}\text { Previous heart failure } \\
\text { Diseased vessels }\end{array}$ & $5(5 \%)$ & $4(7 \%)$ & $1(2 \%)$ \\
\hline 3 & $81(73 \%)$ & $47(76 \%)$ & $34(69 \%)$ \\
\hline 2 & $20(18 \%)$ & $9(15 \%)$ & $10(21 \%)$ \\
\hline$\geq 1+$ left main & $10(9 \%)$ & $6(9 \%)$ & $5(10 \%)$ \\
\hline \multicolumn{4}{|l|}{ LVEF } \\
\hline$>0.50$ & $82(74 \%)$ & $45(73 \%)$ & $37(76 \%)$ \\
\hline $0.30-0.50$ & $29(26 \%)$ & $17(27 \%)$ & $12(24 \%)$ \\
\hline \multicolumn{4}{|l|}{ Distal anastomoses: } \\
\hline 2 & $21(20 \%)$ & $10(16 \%)$ & $11(22 \%)$ \\
\hline 3 & $56(50 \%)$ & $32(52 \%)$ & $24(49 \%)$ \\
\hline 4 & $29(26 \%)$ & $16(26 \%)$ & $13(27 \%)$ \\
\hline 5 & $5(4 \%)$ & $4(6 \%)$ & $1(2 \%)$ \\
\hline \multicolumn{4}{|l|}{ Bypass conduits } \\
\hline LITA + GSV(s) & $90(81 \%)$ & $49(79 \%)$ & $41(84 \%)$ \\
\hline GSV(s) & $17(15 \%)$ & $10(16 \%)$ & $7(14 \%)$ \\
\hline $\begin{array}{l}\text { LITA + RITA or } \\
\text { LRA }\end{array}$ & $4(4 \%)$ & $3(5 \%)$ & $1(2 \%)$ \\
\hline CPB time (min) & $74 \pm 20$ & $76 \pm 21$ & $71 \pm 18$ \\
\hline $\begin{array}{l}\text { Aortic clamp time } \\
\text { (min) }\end{array}$ & $61 \pm 17$ & $64 \pm 17$ & $58 \pm 18$ \\
\hline Normothermic CPB & $55(49 \%)$ & $28(45 \%)$ & $27(55 \%)$ \\
\hline
\end{tabular}

$C P B$, Cardiopulmonary bypass; GSV, great saphenous vein; LITA, left internal thoracic artery; $L R A$, left radial artery; $L V E F$, left ventricular ejection fraction; $R I T A$, right internal thoracic artery.

atively than $\mathrm{C}$-allele carriers $(P<.0001$ for difference between areas under the curve).

\section{Evaluation of Postoperative Renal and Pulmonary Function in the Whole Population and in Relation to IL-6 Promoter Polymorphism}

In the overall population, the mean perioperative differences in serum creatinine, nitrogen, and potassium were $0.53 \pm 0.41,6.86 \pm 7.44$, and $0.60 \pm 0.63$, respectively. Two patients had overt renal insufficiency necessitating temporary hemodyalisis, 44 patients required extra diuretic stimulus, and 21 patients required dopamine at renal dosage in the postoperative period. Two patients had postoperative respiratory insufficiency, and the mean duration of mechanical ventilation was $18.02 \pm 16.56$ hours; the mean respiratory index at 6 hours was $2.56 \pm 0.75$ and at 12 hours was $2.12 \pm 0.77$.
Analysis of postoperative renal function in relation to the IL-6 promoter polymorphism demonstrated a strong association between $\mathrm{G}$ homozygosity and increases in all the investigated renal function indexes (overall effect $P<$ .0001 , see Tables 3 and 4). Similarly, analysis of the indexes of postoperative pulmonary function in relation to the IL-6 promoter polymorphism showed that $\mathrm{G}$ homozygotes had worse respiratory indexes at both 6 and 12 hours and longer ventilation time (overall effect $P<.0001$, Table 3 ).

As already reported, $\mathrm{G}$ homozygosity was associated with longer stay both in the intensive care unit and in the hospital $(2.5 \pm 3.4$ vs $1.4 \pm 0.9$ days and $6.7 \pm 4.0$ vs 5.3 \pm 1.4 days, respectively; $P=.02$ for both).

\section{Correlation Between Postoperative Renal and Pulmonary Complications and IL-6 Levels}

There was a strong correlation between postoperative IL-6 levels and most of the instrumental indexes of renal and pulmonary complications considered. The area under the curve of postoperative IL- 6 correlated significantly with the mean perioperative difference in serum creatinine $(\mathrm{R}=$ $0.65, P=.031$ ), with the respiratory index at 6 and 12 hours $(\mathrm{R}=0.61, P=.041$ and $\mathrm{R}=0.58, P=.041$, respectively $)$, and with longer ventilation time $(\mathrm{R}=0.68, P=.029)$. Similarly, patients who required postoperative use of dopamine at renal dosage or needed extra diuretic stimulus had significantly higher postoperative IL-6 values compared with patients not having complications $(P=.03$ and .02 , respectively, for difference between areas under the curve).

No correlation was found between postoperative IL-6 levels and the mean perioperative difference in serum po$\operatorname{tassium}(\mathrm{R}=0.03, P=.22)$ and for the $\Delta-\mathrm{BUN}(\mathrm{R}=0.05$, $P=.11)$.

\section{Discussion}

With almost 800,000 operations worldwide per year, coronary artery bypass grafting is one of the most frequent surgical procedures performed. The technical and technological improvements that have occurred in the past decade have rendered this operation more safe. Despite that, according to The Society of Thoracic Surgeons cardiac surgery database, about $10 \%$ of patients have significant morbidity after bypass grafting and more than $30 \%$ of them face a postoperative complication.

The use of the extracorporeal circulation, and the consequent whole body systemic inflammatory reaction, plays a major role in determining postoperative morbidity after bypass grafting. In fact, $\mathrm{CPB}$ acts as an enormous inflammatory stimulus and elicits a systemic inflammatory reaction that is thought to be one of the main causes of postoperative organ dysfunction. ${ }^{1}$ The clinical consequences of this CPB-induced systemic inflammatory reaction vary from patient to patient, ranging from a subclinical increase in the 
TABLE 3. Postoperative indexes of renal and pulmonary function according to IL-6 promoter polymorphism (continuous variables)

\begin{tabular}{|c|c|c|c|c|}
\hline Index & $\begin{array}{l}\text { CG + CC } \\
(n=49)\end{array}$ & GG (n = 62) & $\begin{array}{c}\text { Univariate* } \\
\text { ( } P \text { value })\end{array}$ & $\begin{array}{c}\text { Multivariate } \\
(P \text { value })\end{array}$ \\
\hline Respiratory index at 6 hours & $2.1 \pm 0.5$ & $2.9 \pm 0.8$ & .0001 & .0001 \\
\hline Respiratory index at 12 hours & $1.3 \pm 0.1$ & $2.8 \pm 0.3$ & .0001 & .0001 \\
\hline Mechanical ventilation (h) & $12.7 \pm 6.7$ & $22.5 \pm 20.6$ & .0001 & .01 \\
\hline Perioperative $\Delta$-creatinine & $0.18 \pm 0.14$ & $0.82 \pm 0.34$ & .0001 & .0001 \\
\hline Perioperative $\Delta$-potassium & $0.15 \pm 0.48$ & $0.99 \pm 0.44$ & .0001 & .0001 \\
\hline Perioperative $\Delta$-BUN & $2.6 \pm 4.1$ & $10.1 \pm 7.8$ & .0001 & .0001 \\
\hline
\end{tabular}

BUN, Blood urea nitrogen.

*Wilcoxon test.

tMultivariate analysis of variance.

TABLE 4. Postoperative indexes of renal function according to IL-6 promoter polymorphism (discrete variables)

\begin{tabular}{lcccc}
\hline Index & $\begin{array}{c}\text { CG }+\mathbf{C C} \\
(\mathbf{n}=\mathbf{4 9})\end{array}$ & $\begin{array}{c}\text { GG } \\
(\mathbf{n}=\mathbf{6 2})\end{array}$ & $\begin{array}{c}\text { Univariate } \\
\text { [0R (95\% C) })\end{array}$ & $\begin{array}{c}\text { Multivariate* } \\
\text { [0R (95\% CI)] }\end{array}$ \\
\hline Dialysis & 0 & $1(1.6 \%)$ & $0.79(0.05$ to 12.91$)$ & \\
Extra diuretic stimulus & $5(10.2 \%)$ & $39(62.9 \%)$ & $14.9(5.2$ to 43.0$)$ & $16.5(4.7$ to 57.6$)$ \\
Dopamine at renal dose & $2(4.1 \%)$ & $19(30.7 \%)$ & $10.4(2.3$ to 47.2$)$ & $29.4(3.5$ to 248$)$ \\
\hline
\end{tabular}

*Multivariate logistic regression analysis.

tNot performed due to the small number of events.

humoral inflammatory indexes to multiple organ insufficiency and even death. ${ }^{1,2}$

The kidneys and the lungs are probably the main targets of the postoperative systemic inflammatory reaction ${ }^{4-6}$; renal and pulmonary dysfunction account for a large portion of the global number of complications, worsening significantly the short- and midterm prognosis of patients undergoing coronary bypass grafting. ${ }^{11-17}$

Traditionally, attempts to explain the heterogeneous clinical expressions of the systemic inflammatory syndrome in different patients and to quantify the individual surgical risk have focused on the preoperative functional reserve of the various organs and systems. ${ }^{3}$

The hypothesis of a genetic modulation of the inflammatory response to $\mathrm{CPB}$ and, thus, of the postoperative outcome has received, to date, only limited attention. To the best of our knowledge, only Chew and associates have shown how postoperative renal dysfunction is associated with the $\epsilon 4$ polymorphism of the gene for the apolipoprotein $\mathrm{E}$, which plays a significant role in the mediation of the inflammatory and tissue repair reactions. ${ }^{10}$

Recently, a preliminary study performed by our group showed that another gene involved in the modulation of the inflammatory reaction, the IL-6 gene promoter, modulates the postoperative blood levels of the corresponding cytokine and is associated with the duration of in-hospital and intensive care unit stays. ${ }^{7}$ However, in the preliminary report, the postoperative outcome was assessed by simple clinical cri- teria and no correlation between the IL- $6-174 \mathrm{G} / \mathrm{C}$ polymorphism and morbidity could be found.

The results of the present study conducted in the same population using more sensible indexes for the evaluation of postoperative outcome show that the IL- $6-174$ G/C genotype is strongly associated, not only with the magnitude of the postoperative systemic inflammatory reaction but also with the degree of postoperative renal and pulmonary dysfunction.

In fact, $\mathrm{G}$ homozygotes have significantly worse postoperative pulmonary and renal function than do $\mathrm{C}$-allele carriers, and there is a strong correlation between the magnitude of the inflammatory reaction to surgery and postoperative pulmonary and renal morbidity.

These data should be interpreted with consideration given to the limitations of our study. Despite the fact that the FIFA protocol is by far one of the largest prospective studies on the postoperative inflammatory activation after cardiac surgery, the sample size of our study does not allow us to definitely rule out type II statistical errors, especially with regard to the multivariable analysis. Moreover, the clinical relevance of the markers of pulmonary and renal dysfunction that we have chosen remains, at least in part, undemonstrated. However, the strong statistical association between G homozygosis, postoperative IL-6 levels, and both pulmonary and renal dysfunction; the fact that the method used for renal function evaluation has been validated in cardiac surgery patients by others, ${ }^{10}$ and the finding 
that $\mathrm{G}$ homozygotes had a longer in-hospital stay after surgery seem to limit the possibility that these considerations can significantly affect the main findings of the study.

In conclusion, in a highly selected series of patients undergoing primary isolated coronary artery bypass grafting, we have found that the IL- $6-174 \mathrm{G} / \mathrm{C}$ polymorphism modulates the inflammatory response to surgery and, via this, is associated with the degree of postoperative renal and pulmonary dysfunction and with the length of in-hospital stay. These findings confirm the major role of the postoperative systemic inflammatory reaction to CPB in determining pulmonary and renal complications after cardiac surgery, and, for one of the first times, suggest the existence of a genetic modulation of the postoperative outcome.

\section{References}

1. Kirklin JK, Westaby S, Blackstone EH, Kirklin JW, Chenoweth DE, Pacifico AD. Complement and the damaging effect of cardiopulmonary bypass. J Thorac Cardiovasc Surg. 1983;86:845-57.

2. Butler J, Rocker GM, Westaby S. Inflammatory response to cardiopulmonary bypass. Ann Thorac Surg. 1993;55:552-9.

3. Hammermeister KE, Burchfiel C, Johnson R, Grover FL. Identification of patients at greatest risk for developing major complications at cardiac surgery. Circulation. 1990;82(Suppl IV):IV380-9.

4. Conlon PJ, Stafford-Smith M, White WD, Newman MF, King S, Winn MP, at al. Acute renal failure following cardiac surgery. Nephrol Dial Transplant. 1999;14:1158-62.

5. Mangano CM, Diamondstone LS, Ramsay JG, Aggarwal A, Herskowitz A, Mangano DT. Renal dysfunction after myocardial revascularization: risk factors, adverse outcome, and hospital resource utilization. The Multicenter Study of Perioperative Ischemia Research Group. Ann Intern Med. 1998;128:194-203.

6. Cain HD, Stevens PM, Adaniya R. Preoperative pulmonary function and complications after cardiovascular surgery. Chest. 1979;76:130-5.

7. Burzotta F, Iacoviello L, Di Castelnuovo A, Glieca F, Luciani N, Zamparelli R, et al. Relation of the $-174 \mathrm{G} / \mathrm{C}$ polymorphism of interleukin-6 to interleukin-6 plasma levels and to length of hospital- ization after surgical coronary revascularization. Am J Cardiol. 2001; 88:1125-8.

8. Gaudino M, Zamparelli R, Andreotti F, Burzotta F, Iacoviello L, Glieca F, et al. Normothermia does not improve postoperative hemostasis nor reduce inflammatory activation in patients undergoing primary isolated coronary artery bypass. $J$ Thorac Cardiovasc Surg. 2002;123:1092-100.

9. Fishman D, Faulds G, Jeffery R, Mohamed-Ali V, Yudkin JS, Humphries $S$, et al. The effect of novel polymorphisms in the interleukin-6 (IL-6) gene on IL-6 transcription and plasma levels, and an association with systemic-onset juvenile chronic arthritis. J Clin Invest. 1998;102:1369-76.

10. Chew STH, Newman MF, White WD, Conlon PJ, Saunders AM, Strittmatter WJ, et al. Preliminary report on the association of apolipoprotein E polymorhisms with postoperative peak serum creatinine concentrations in cardiac surgical patients. Anesthesiology. 2000;93: 325-31.

11. Chertow GM, Lazarus JM, Christiansen CL, Cook EF, Hammermeister KE, Grover F, et al. Preoperative renal risk stratification. Circulation. 1997;95:878-84.

12. Page US, Washburn T. Using tracking data to find complications that physicians miss: the case of renal failure in cardiac surgery. Jt Comm J Qual Improv. 1997;23:511-20.

13. Chertow GM, Levy EM, Hammermeister KE, Grover F, Daley J. Independent association between acute renal failure and mortality following cardiac surgery. Am J Med. 1998;103:343-8.

14. Weerasinghe A, Hornick P, Smith P, Taylor K, Ratnatunga C. Coronary artery bypass grafting in nondyalisis-dependent mild to moderate renal dysfunction. J Thorac Cardiovasc Surg. 2001;121:1083-9.

15. Braun SR, Birnbaum ML, Chopra PS. Pre- and postoperative pulmonary function abnormalities in coronary artery revascularization surgery. Chest. 1978;73:316-20.

16. Gale GD, Teasdale SJ, Sanders DE, Bradwell PJ, Russell A, Solaric B, et al. Pulmonary atelectasis and other respiratory complications after cardiopulmonary bypass and investigation of aetiological factors. Can Anaesth Soc J. 1979;26:15-21.

17. Milot J, Perron J, Lacasse Y, Letourneau L, Cartier PC, Maltais F. Incidence and predictors of ARDS after cardiac surgery. Chest. 2001; 119:884-8. 